\title{
Basic disturbances of information processing in psychosis prediction
}

\section{Mitja Bodatsch*, Joachim Klosterkötter, Ralf Müller and Stephan Ruhrmann}

Department of Psychiatry and Psychotherapy, University of Cologne, Cologne, Germany

Edited by:

Jun Soo Kwon, Seoul National

University, South Korea

\section{Reviewed by:}

Terry E. Goldberg, The Feinstein

Institute for Medical Research, USA

Raimo Kalevi Rikhard Salokangas,

University of Turku, Finland

${ }^{*}$ Correspondence:

Mitja Bodatsch, Department of Psychiatry and Psychotherapy,

University of Cologne, Kerpener

Strasse 62, 50924 Cologne, Germany

e-mail: mitja.bodatsch@uk-koeln.de
The basic symptoms (BS) approach provides a valid instrument in predicting psychosis onset and represents moreover a significant heuristic framework for research. The term "basic symptoms" denotes subtle changes of cognition and perception in the earliest and prodromal stages of psychosis development. BS are thought to correspond to disturbances of neural information processing. Following the heuristic implications of the BS approach, the present paper aims at exploring disturbances of information processing, revealed by functional magnetic resonance imaging (fMRI) and electro-encephalographic as characteristics of the at-risk state of psychosis. Furthermore, since high-risk studies employing ultra-high-risk criteria revealed non-conversion rates commonly exceeding 50\%, thus warranting approaches that increase specificity, the potential contribution of neural information processing disturbances to psychosis prediction is reviewed. In summary, the at-risk state seems to be associated with information processing disturbances. Moreover, fMRI investigations suggested that disturbances of language processing domains might be a characteristic of the prodromal state. Neurophysiological studies revealed that disturbances of sensory processing may assist psychosis prediction in allowing for a quantification of risk in terms of magnitude and time. The latter finding represents a significant advancement since an estimation of the time to event has not yet been achieved by clinical approaches. Some evidence suggests a close relationship between self-experienced BS and neural information processing. With regard to future research, the relationship between neural information processing disturbances and different clinical risk concepts warrants further investigations. Thereby, a possible time sequence in the prodromal phase might be of particular interest.

Keywords: basic symptoms, EEG/ERP, fMRI, prediction of psychosis, ultra-high risk

\section{INTRODUCTION}

Disturbances of information processing are a core feature of psychosis, particularly schizophrenia, with a significant impact on vulnerability and course $(1,2)$. Hence, with regard to the prediction of conversion to psychosis, indicators of such alterations are of special interest.

In the present review, we will consider three major areas of research, the basic disturbances concept and the event-related research employing either electro-/magnet-encephalographic (EEG/MEG), or functional magnetic resonance imaging (fMRI). Thereby results are emphasized that allow for a detection of those subjects clinically at high risk (3), who indeed developed a psychotic disorder.

"Basic symptoms" (BS) are conceptualized as a phenomenological counterpart of neural pathological changes in brain functioning and have been demonstrated to represent core features of psychotic disorders (4-8). These symptoms point to subtle, predominately only self-experienced disturbances in drive, affect, thinking, speech, perception, motor action, central vegetative functions, and stress tolerance, with full insight into their pathologic nature (8). The BS concept assumes that these subjective impairments are closely related to the pathophysiological aberrations underlying psychosis development $(4,6)$. Thus, the concept corresponds to the "subjective cognitive impairment" discussed as a risk indicator for dementia $(9,10)$. In their seminal psychopathological works on the BS concept, Süllwold and Huber (11) and Klosterkötter (12) conceived a three-domain model of the relationship between symptoms and pathophysiology changes, differentiating between a pre-phenomenal, a trans-phenomenal, and a phenomenal domain. The pre-phenomenal domain corresponds to the neurophysiological and neurochemical correlates of brain functioning. Aberrations in this domain lead to disturbances of neurocognitive processes, including de- and en-coding of information, gating, etc., and representing the trans-phenomenal domain. These disturbances are the source of the self-experienced BSs, which thus flag the transition from the trans-phenomenal to the phenomenal level and are understood as the basis for the further development of psychotic symptoms. The gradual transition toward full-blown positive symptoms interferes with the preexisting collective and individual anthropological information inventory that provides the patient's cognitive scheme to explain aberrant cognitive-perceptive experiences (12). Thus, different to the BS, content and severity of positive symptoms are only distant, indirect reflections of the underlying pathophysiology, an 
assumption, which corresponds well to a recent model of psychosis development (13).

In line with the assumption of a close relationship to neurobiological changes, BS represent not only the earliest symptoms of psychosis development, but almost persistent phenomena that can be observed independently of positive and/or negative symptoms throughout large periods of the course of illness $(5,7,14,15)$.

Since BS are thought to mark the earliest stages of psychosis development, they have been employed to the aim of identifying subjects in presumably pre-psychotic stages of illness $(7,8,14-$ 16). The specificity of BS, which may be almost unspecific in the very early stages of psychosis development, has been thought to increase in the proximal pre-psychotic, legitimately called "prodromal" phase. In the yet largest study employing BSs to predict psychosis onset, $70 \%$ of the participants suffering from at least one BS developed schizophrenia within approximately 5 years, and $37 \%$ within the first 24 months of follow-up (14). Subsequent investigations have led to the establishment of two well-defined criteria, pointing either to a collection of highly predictive cognitive and perceptive disturbances (COPER) or to predominantly cognitive disturbances (COGDIS), respectively (7) (see Table $\mathbf{1}$ for an overview of the relevant cognitive and perceptive BSs). Subjects qualifying for the COPER criterion developed psychosis in $34.9 \%$ within 11 months on average (range 1-37, median 9 months) (17). The BS approach hence represents a valuable component in prediction research. However, the assessment of BS requires highly trained raters, particularly since insight and coping capability decline with the progression to full-blown psychosis (15).

Table 1 | Predictive basic symptoms.

\begin{tabular}{|c|c|c|}
\hline Symptom & Description & Phenomenology \\
\hline Thought interference & $\begin{array}{l}\text { Intrusion of completely insignificant thoughts } \\
\text { hindering concentration }\end{array}$ & "I can't help thinking about other things, which is very distracting" \\
\hline Thought perseveration & $\begin{array}{l}\text { Obsessive like repetition of insignificant } \\
\text { thoughts or mental images }\end{array}$ & $\begin{array}{l}\text { "I always have to mull over what I just said. I can't stop thinking about } \\
\text { what I might have said wrong or what I could have added although I really } \\
\text { don't think that anything was wrong with what I said" }\end{array}$ \\
\hline Thought pressure & Self-reported "chaos" of unrelated thoughts & $\begin{array}{l}\text { "If I am stressed out my mind gets chaotic and I have great problems } \\
\text { thinking straight. Too many thoughts come up at once" }\end{array}$ \\
\hline Thought blockages & Sudden loss of the thread or train of thoughts & "Sometimes my thoughts just stop, are suddenly gone, like being cut off" \\
\hline $\begin{array}{l}\text { Disturbance of } \\
\text { receptive language }\end{array}$ & $\begin{array}{l}\text { Paralysis in the immediate comprehension of } \\
\text { simple words/sentences, either read or heard }\end{array}$ & "I often can't get the meaning of common words when I am reading" \\
\hline $\begin{array}{l}\text { Disturbance of } \\
\text { expressive speech }\end{array}$ & $\begin{array}{l}\text { Problems in producing appropriate words, } \\
\text { sometimes experienced as a reduction in } \\
\text { active vocabulary }\end{array}$ & $\begin{array}{l}\text { "Sometimes I think it must appear as if English were really my second } \\
\text { language, like I don't know English very well because I have difficulties } \\
\text { expressing myself. I forget the words" }\end{array}$ \\
\hline $\begin{array}{l}\text { Disturbances of } \\
\text { abstract thinking }\end{array}$ & $\begin{array}{l}\text { Inability to explain abstract contexts, sayings, } \\
\text { or idioms }\end{array}$ & $\begin{array}{l}\text { "Sometimes I get puzzled if a certain object or event only stands as a } \\
\text { metaphor for some more general, abstract, or philosophical meaning" }\end{array}$ \\
\hline $\begin{array}{l}\text { Inability to divide } \\
\text { attention }\end{array}$ & $\begin{array}{l}\text { Interference of two non-demanding tasks on } \\
\text { different sensual domains (e.g., verbal } \\
\text { dialogue and motor action) }\end{array}$ & $\begin{array}{l}\text { "Doing two things at once has become impossible even with the } \\
\text { simplest things. I always have to concentrate on one thing at a time" }\end{array}$ \\
\hline Captivation of attention & $\begin{array}{l}\text { Involuntary captivation by details of the } \\
\text { visual field that catches and holds the look. }\end{array}$ & $\begin{array}{l}\text { "Sometimes an object really seems to stand out from the rest of what I } \\
\text { see. My eyes then fix on it. It's like being spellbound" }\end{array}$ \\
\hline $\begin{array}{l}\text { Decreased ability to } \\
\text { discriminate between } \\
\text { perception and ideas }\end{array}$ & $\begin{array}{l}\text { The ability to allocate mental representations } \\
\text { to their proper domain, e.g., to discriminate } \\
\text { memory and fantasy }\end{array}$ & $\begin{array}{l}\text { "I thought about my grandparents. Then a weird thing happened: I } \\
\text { couldn't remember if I knew my grandparents properly, if they were real, } \\
\text { or if they were just in my imagination" }\end{array}$ \\
\hline $\begin{array}{l}\text { Unstable ideas of } \\
\text { reference }\end{array}$ & $\begin{array}{l}\text { Feelings of being directly addressed by a } \\
\text { non-intentional environment with insight }\end{array}$ & $\begin{array}{l}\text { "When I was listening to the radio the idea that the lyrics had some } \\
\text { special meaning for me suddenly popped up into my head" }\end{array}$ \\
\hline Derealization & $\begin{array}{l}\text { Feelings of being detached from an "unreal" } \\
\text { environment }\end{array}$ & $\begin{array}{l}\text { "Sometimes, I feel disconnected from the world around me, like I'm } \\
\text { under a glass cover" }\end{array}$ \\
\hline $\begin{array}{l}\text { Visual or acoustic } \\
\text { perceptual disturbances }\end{array}$ & $\begin{array}{l}\text { Perceptual observations, e.g., a wrong } \\
\text { coloring, distorted shape, or changed sound } \\
\text { quality/intensity with insight }\end{array}$ & "People suddenly seemed changed and had different hair colors" \\
\hline
\end{tabular}

Adapted from Schultze-Lutter (15), with modifications. For COPER/COGDIS see Schultze-Lutter et al. (17). 
Furthermore, the valid evaluation of BS is often disabled by acute and/or prominent (attenuated) psychotic symptoms (15).

The currently most widely used clinical criteria of psychosis prediction are the so called ultra-high-risk (UHR) symptoms (18). According to this approach, either attenuated psychotic symptoms (APSs) or brief, spontaneously remitting psychotic symptoms (BLIPSs) or a genetic liability in combination with an actual loss of functioning indicate a markedly increased risk for an imminent onset of full-blown psychosis (19). Although clinical studies during the recent decades have demonstrated that the prediction of psychosis is fairly possible this way, the respective research has simultaneously unearthed its main challenge: against the expectation, the majority of persons considered being in a pre-psychotic state does not develop full-blown psychosis in the foreseeable future (20). The clinical prediction of psychosis thus inherits significant uncertainty, as mirrored by non-conversion rates commonly exceeding 50\% (at least within the available, almost too short observation periods) (21). Approaches that increase specificity are thus warranted.

Following the heuristic implications of the BS approach it can be assumed that the uncertainty of prediction results from an inherent ambiguity of (attenuated) psychotic symptoms. UHR criteria presumably represent disturbances of higher order integrative functions, reality testing, inner monitoring, and context evaluation possibly arising from various neural aberrations that do not necessarily comprise the specific processes leading to the development of, e.g., schizophrenia. The "prodrome," however, is presumably characterized by specific disturbances of neural processing that are not mirrored by rather unspecific psychotic phenomena $(11,12,21-24)$. In line with this, it could be hypothesized that in a population of persons clinically at-risk of developing psychosis, certain neural "markers" may assist in validly differentiating between future converters, i.e., persons displaying a truly prodromal state, and non-converters although these groups are clinically indistinguishable (25). In this regard, it appears not necessary that the hypothesized markers represent direct correlates of the observed clinical (psychotic) symptoms; it would be sufficient if their presence significantly increases the probability that the respective person converts to psychosis. From the view of the BS concept, disturbances of information processing seem to be the most promising candidates to this purpose since these have phenomenologically been demonstrated independent of psychotic symptoms $(14,15)$. Predictive BS display a low prevalence (particularly in comparison to subclinical psychotic symptoms) in the general population and in non-psychotic samples $(26,27)$. Moreover, even though some subtle, progressive structural changes might already occur in the pre-psychotic phase (28), functional disturbances may account best for the "fluid" dynamics of the atrisk state $(22,29)$. Objective measures provided by neuroimaging and neurophysiology, respectively, raise the opportunity to observe disturbances of information processing directly.

In the present paper, following the BS concept, we aim at exploring if and to what extent objective parameters of neural information processing allow for improving the prediction of psychosis onset. After an overview of the research on disturbances of neural information processing in the at-risk state, we will focus on findings indicating predictive capabilities.

\section{METHODS}

We used the following Medical Subject Heading (MeSH) categories: (fMRI OR EEG OR MEG) AND [UHR OR prodrome OR at-risk mental state (ARMS) OR clinical high risk (3)] AND (psychosis OR schizophrenia). Studies were screened for the employment of current risk criteria (COPER/COGDIS, UHR) and only studies based on clinical criteria were included. While not selecting for paradigms, inclusion was restricted to investigations employing fMRI, EEG, and MEG, respectively. The detailed review focused on studies comprising converters in the respective high-risk samples.

\section{INFORMATION PROCESSING IN PSYCHOSIS DEVELOPMENT FUNCTIONAL NEUROIMAGING}

A broad body of literature has verified deficits associated with psychotic disorders by functional neuroimaging (fMRI). Particularly the functionality of the prefrontal cortex, contributing to executive and working memory functions, and moreover subserving emotion processing, reward, and social cognition, has been demonstrated to be impaired in schizophrenia (30).

\section{High-risk state}

Investigations employing tasks related to attention control, verbal fluency, and working memory, respectively, suggested almost consistently a gradual decline in frontal and striatal activation from the clinical risk state to chronic psychosis $(30,31)$. Further evidence suggests an impairment of fronto-temporal connectivity (30). Other studies demonstrated alterations in the neural correlates of emotion processing (32) and movement generation (33), respectively. Overall, the observed deficits tend to be significant compared to controls and tantamount, although less severe, compared to first-episode psychosis $(30,31)$.

A recent meta-analysis demonstrated a prefrontal dysfunction in the at-risk state across different paradigms (31). Additionally, reduced activation patterns have consistently been found in the anterior cingulate, the medial and superior frontal gyrus, and the inferior frontal gyrus, respectively (31). The anterior cingulate is involved in conflict monitoring, social cognition, and emotional processing $(34,35)$. The aforementioned areas of the frontal gyrus contribute to executive and memory functions (35). The inferior frontal gyrus has been demonstrated to be particularly involved in language processing with the observed deficits in at-risk subjects possibly relating to elevated dopamine in striatal regions $(36,37)$.

\section{Prodromal state}

Two studies yet compared fMRI measures in converters vs. nonconverters (38-41). They focused on language processing and verbal fluency, respectively (39-41). Sabb and colleagues demonstrated a higher activation in the temporal lobes, the frontal operculum, the left precentral gyrus, the caudate, and striatal regions of future converters during the semantic logic condition of a language processing task (42). The authors reported a significant relationship between the left inferior frontal gyrus, the temporal lobe, the frontal gyrus, and psychopathological measures of thought disorder (42). The activation patterns in the anterior cingulate and the inferior frontal gyrus were inversely correlated with social adjustment scores at follow-up (42). Allen et al. demonstrated an increased activation in future converters, too, with regard to 
the left superior frontal gyrus, the middle frontal gyrus, parts of the brainstem, and the left hippocampus in a verbal fluency task (41). The authors additionally demonstrated an increased midbrain-prefrontal functional connectivity and an increased striatal dopamine metabolism in these subjects (41). Both studies, however, did not report any predictive models.

Taken together, functional disturbances in at-risk subjects have consistently been demonstrated, thereby pointing particularly to dysfunctions of frontal regions. However, definite conclusions should be deferred since the published fMRI studies vary markedly with regard to both, methodology and paradigms. Furthermore, the number of studies investigating differential deficits in converters and non-converters is yet sparse and none of the available studies reported discriminative statistics as required for predictor models.

\section{NEUROPHYSIOLOGY}

Contrary to the antecedent axiom that sensory brain regions simply relay neural representations of the environment to higher order networks, the very high complexity of early sensory information processing has to be appreciated: even at the earliest stages of sensory processing, incoming information is preconsciously filtered and digested via top-down and bottom-up loops (43). In focusing on sensory dysfunction as a potential etiological factor, neurophysiological research in the recent decades has revealed significant deficits in encephalographic correlates (EEG/MEG) of early information processing in schizophrenia. In this regard, the auditory system has been most extensively investigated, while sensory processing deficits are not restricted to this domain $(43,44)$. A recent investigation, for instance, demonstrated the intertwining of visual perception and higher order processing in a facial affect recognition task (45).

However, typical paradigms point to event-related potentials (42) appearing within $350 \mathrm{~ms}$ after stimulus presentation (43, 46-48). These ERPs are thought to straddle neural processing of increasing complexity from bottom pre-attentive filter functions to downstream sensory memory processing already involving attention control (43, 46-48).

\section{High-risk state}

Overall, sensory processing deficits in subjects displaying high-risk symptoms have been demonstrated to encompass the full range of processing, i.e., early as well as later stages. However, it is not yet clear how the observed disturbances differentially relate to the pathophysiology of psychosis development.

One of the earliest steps in neural processing contributes to filtering of sensory information. In at-risk subjects, significant deficits of the respective correlates have been demonstrated in studies on sensory gating (P50/N100 components) and prepulse inhibition (PPI) paradigms $(47,49-54)$. Although conceptualized as a pre-attentive measure, however, PPI might be moderated by selective attention (55). With regard to sensory gating, the majority of studies have found some though not all measures to be reduced in the clinical high-risk state, possibly tantamount to deficits observed in first-episode schizophrenia (47, 49-52). Neuroanatomically, temporoparietal, prefrontal, and hippocampal structures are thought to contribute to gating phenomena with the hippocampus regions CA3 being particularly involved in the later phases of stimulus processing $(56,57)$. Neurochemically, cholinergic neurotransmission via low-affinity nicotinic receptors and noradrenergic signaling through alpha-2-receptors has been found to particularly contribute to sensory gating (58).

Later stages of sensory information processing occupy the interface between perceptual and cognitive systems. A commonly used paradigm involves neural ability to discriminate deviant stimuli in a series of predictable standards $(43,46,48)$. The mismatch negativity (MMN), which is thought to relate to context updating, may be significantly impaired in subjects at UHR compared to healthy controls $(25,50,59-64)$. In comparison to first-episode psychosis, most studies demonstrated no statistically significant differences, and did neither find significant differences in comparison to recent onset psychosis, but a more pronounced deficit in at-risk subjects compared to chronic psychosis $(25,50,59$, $61,62,65)$. However, the number of future converters in the respective samples might significantly contribute to these statistical results and non-conversion may be associated with less severe or no MMN deficits $(25,59,61,63,65)$. MMN deficits are currently best documented as potential markers of progression toward full-blown psychosis. Neural generators of the MMN have been localized bilaterally in the temporal cortex and in frontal regions with a predominance of the right hemisphere in tone paradigms and left sided generators in language paradigms (66). There may be two subcomponents of the MMN, the first generated in the superior temporal gyrus and the second in the inferior frontal gyrus, respectively $(66,67)$. The $\mathrm{MMN}$ seems to rely on glutamatergic and GABAergic neurotransmission, respectively, since the NMDA-receptor antagonist ketamine has repeatedly been shown to diminish MMN without affecting ERPs of similar latency and GABAergic substances have been demonstrated to attenuate MMN (58, 68, 69).

Investigations employing the $\mathrm{P} 3$ component, which is thought to reflect automatic processing of novelty and memory updating, have demonstrated significant deficits in at-risk subjects compared to healthy controls $(44,59,62,65,70-76)$. Thereby, the P3 deficit in the at-risk state seems to be tantamount to the impairment observed in first-episode psychosis, but less severe compared to recent onset and chronic schizophrenia, respectively $(44,59,62$, $65,72,75)$. The P3 has been suggested as a potential marker of illness progression (73), but might more broadly indicate cognitive disturbances $(58,77)$. A recent investigation demonstrated a relationship between $\mathrm{P} 3$ and disturbances in receptive language in subjects displaying psychotic-like experiences (78). The P3 has been demonstrated to relate to frontal and posterior regions, particularly to precentral areas, insula, the parietal, and the inferior temporal cortex $(56,57)$. Since the $\mathrm{P} 3$ reflects higher order cognitive processes involved in attention and memory, it is sensitive to manipulations of various neurochemical pathways (58). Cholinergic stimulation, however, has been shown to rather specifically alter P3 (58).

\section{Prodromal state}

Nine studies have been identified that statistically compared neurophysiological measures in converters vs. non-converters $(25,47$, 50, 52, 53, 61, 63, 70, 71, 73) (see Table 2 for overview). 
Table 2 | Event-related potentials and prepulse inhibition in converters and non-converters.

\begin{tabular}{|c|c|c|c|c|c|c|}
\hline Study & Parameter & $\begin{array}{l}N \text { at-risk } \\
\text { (transitions) }\end{array}$ & $\begin{array}{l}\text { Mean time } \\
\text { to transition } \\
\text { (months } \pm \text { SD) }\end{array}$ & $\begin{array}{l}\text { Predictive } \\
\text { model } \\
\text { reported }\end{array}$ & $\begin{array}{l}\text { ARMS-T } \\
\text { vs. } \\
\text { ARMS-NT }\end{array}$ & Diagnoses after transition \\
\hline Ziermans et al. (53) & PPI & $42(6)$ & Not reported & No & $\downarrow$ & $\begin{array}{l}\text { Schizophrenia }(N=4) \text {, schizoaffective } \\
\text { disorder }(N=1) \text {, bipolar disorder }(N=1)\end{array}$ \\
\hline $\begin{array}{l}\text { Brockhaus-Dumke et } \\
\text { al. (47) }\end{array}$ & Sensory gating & $39(21)$ & Not reported & No & $\leftrightarrow$ & $\begin{array}{l}\text { Schizophrenia }(N=20) \text {, schizoaffective } \\
\text { disorder }(N=1)\end{array}$ \\
\hline Hsieh et al. (50) & $\begin{array}{l}\text { Sensory gating } \\
\text { MMN }\end{array}$ & $67(11)$ & Not reported & No & $\leftrightarrow$ & Not reported \\
\hline van Tricht et al. (52) & Sensory gating & $61(18)$ & Not reported & No & $\downarrow$ & $\begin{array}{l}\text { Schizophrenia }(N=12) \text {, schizophreniform } \\
\text { disorder }(N=3) \text { schizoaffective disorder } \\
(N=2) \text {, brief psychotic disorder }(N=1)\end{array}$ \\
\hline Bodatsch et al. (25) & MMN amplitude & $62(25)$ & $7.0 \pm 7.0$ & Yes & $\downarrow$ & $\begin{array}{l}\text { Schizophrenia }(N=23) \text {, schizoaffective } \\
\text { disorder }(N=1) \text {, delusional disorder }(N=1)\end{array}$ \\
\hline Shaikh et al. (63) & MMN amplitude & $41(10)$ & $26.5 \pm 26.6$ & No & $\downarrow$ & $\begin{array}{l}\text { Schizophreniform disorder }(N=9) \text {, bipolar } \\
\text { disorder }(N=1)\end{array}$ \\
\hline Higuchi et al. (61) & MMN amplitude & $17(4)$ & Not reported & No & $\downarrow$ & Schizophrenia \\
\hline van Tricht et al. (73) & P300 amplitude & $61(18)$ & $9.4 \pm 7.2$ & Yes & $\downarrow$ & Not reported \\
\hline $\begin{array}{l}\text { Fusar-Poli et al. (70, } \\
71)\end{array}$ & P300 amplitude & $39(10)$ & Not reported & No & $\leftrightarrow$ & Not reported \\
\hline
\end{tabular}

PPI, prepulse inhibition; MMN, mismatch negativity; ARMS-T/-NT, at-risk mental state-transition/non-transition.

The arrows pointing downwards indicate a deficit in converters (independent of polarity of the respective ERP).

Ziermans and colleagues suggested a differential PPI deficit in converters and non-converters (53). Sensory gating measures were investigated by three studies $(47,50,52)$. Thereof, two $(47,50)$ did not find significant differences between converters and nonconverters. The $\mathrm{P} 3$ amplitude was demonstrated to be exclusively disturbed in future converters by one study (73), but to be unimpaired by another investigation $(70,71)$. Of the four published studies evaluating the MMN $(25,50,61,63)$, three consistently demonstrated a MMN deficit in future converters compared to non-converters $(25,61,63,79)$.

Predictive models employing neurophysiological parameters were provided by two published investigations $(25,73)$. Following a group of UHR subjects for 3 years, van Tricht and colleagues demonstrated that later converters to psychosis could be detected by deficits of the PSamplitude at baseline (73). Bodatsch et al. provided evidence that MMN amplitude deficits predict psychosis onset (25). This finding has recently been independently replicated (79). Based on a prognostic score derived from an MMN based Cox regression model, it was furthermore possible to generate two risk classes showing significantly different survival curves. Thus, it was possible to further stratify not only the risk for conversion (hazard rates 0.34 vs. 0.85 ) but also the mean times to event (20 vs. 13 months) (25).

Taken together, correlates of sensory processing and pending higher order functions indicate significant disturbances of neural information processing in at-risk subjects. Future research has to elucidate the pathophysiological meaning of these disturbances and their impact with regard to different outcomes of the atrisk state. However, first steps have been made to identify neural markers of psychosis development.

\section{DISCUSSION \\ INFORMATION PROCESSING DISTURBANCES IN PRODROMAL STATES OF PSYCHOSES}

Impairments of neural information processing in the prepsychotic state have been demonstrated by a rising number of investigations, thereby providing evidence for the heuristic implications of the BS concept. However, although studies employing fMRI measures are sparse compared to investigations focusing on neurophysiology, significant evidence for information processing deficits is provided across methods and paradigms.

Functional magnetic resonance imaging studies most consistently demonstrated dysfunctions of regions differentially contributing to executive and memory functions, social cognition, emotional processing, and language processing, respectively (30, 31). Neurophysiological studies have provided large evidence for impairments of information processing, spanning from the earliest stages of sensory filtering up to memory and attention $(25,47$, 49-54, 59-64, 72-76, 79).

However, since most studies did not comprise converters in their high-risk samples. As a considerable part of theses samples may not proceed to psychosis or even remit (at least clinically and temporally) from the at-risk state $(23,80,81)$, the meaning of the respective findings is not yet clear. They may characterize 
early, subclinical stages of psychotic disorders or an increased vulnerability or transient changes $(20,22,23)$.

\section{PREDICTING PSYCHOSIS ONSET BY INFORMATION PROCESSING DISTURBANCES}

Although fMRI investigations have demonstrated significant differences between converters and non-converters $(41,42)$, no predictive model has been reported in the respective publications. This, however, represents the litmus test for any potential indicator of an increased risk for developing a psychotic disorder.

Regarding neurophysiology, two studies yet established predictive models $(25,73)$ based on ERPs. Another approach integrating psychopathological and biological parameters in a one-step model has recently demonstrated increasing specificity of prediction (82).

However, since only one study investigated the $\mathrm{P} 3$ as a predictor of psychosis onset, this finding needs further corroboration.

Mismatch negativity amplitude reductions may predict conversion to psychosis and enable the stratification of risk into different classes (25). The respective classes have been demonstrated to differ significantly with regard to time to transition (25). Regarding sensory gating measures, progressive alterations may be associated with a prodromal development (52), but the observed deficits failed a correlation with the time until transition (52). However, sensory gating deficits seem to be moderated by the stage of illness since chronic schizophrenia patients exhibit more pronounced deficits compared to at-risk subjects $(47,50)$.

Sensory gating presumably refers to early pre-attentive processes, whereas P3 likely represents cognitive management of salient stimuli, and MMN may straddle bottom-up stimulus registration and top-down change detection. In synopsis of the currents literature, sensory gating deficits might predominantly indicate liability to psychotic experiences, P3 might be primarily susceptible to cognitive disturbances, and the MMN may be best suited to support the identification of future converters.

\section{FRAMING FUTURE RESEARCH}

The heuristic implications of the BS concept predict that disturbances of information processing can be observed largely independent of positive symptoms and are closely related to particular aberrations of brain functioning $(6,11,12,14,15)$. However, although disparate with regard to the method, fMRI, neurophysiological measures, and BS psychopathology may thus converge on particular domains. Although recent investigations did not yet explicitly aim to elucidate this convergence, some results seem useful to generate future research hypotheses.

Among the most predictive BS, two concern disturbances of language processing $(8,14,15)$. The left inferior frontal gyrus (IFG) is recruited in both, speech production and comprehension (83). fMRI investigations comparing converters and non-converters suggest differential disturbances located in the left IFG $(31,42)$. Correlations of IFG activity and increased striatal dopamine have been demonstrated in persons at-risk of psychosis $(31,37)$, and normalization of IFG activity has been associated with a favorable course of the risk syndrome (39). In turn, Sabb and colleagues demonstrated an inverse relationship between IFG activity and future functioning (42). Furthermore, neural generators of the MMN have been located in the IFG (66). The P3 might be related to domains involved in language processing as well (78). At least, an intertwining of the P3 with dysfunctions of language comprehension has been found in subjects displaying psychotic-like experiences (78). Taken together, it can be hypothesized that the language related BS may be mirrored by particular EEG disturbances that relate to language processing domains, which have been found aberrantly activated in fMRI investigations. Apart from that, the evidence for a close relationship between BS phenomenology and particular neural activity appears yet less univocal. However, deficits in neurophysiological parameters seem to be more closely related to cognitive deficits than to psychotic symptoms (77). Sensory gating measures, for instance, have been found to correlate with impairments in sustained attention (77), although this finding is not uncontested, and attention disturbances have been identified as predictive symptoms in prospective studies employing BS criteria $(8,14,15)$. In turn, correlations of gating measures to positive or negative symptoms have been denied by the majority of studies (77).

The relationship between BS and particular brain regions has still to be investigated directly. However, the synopsis of the current literature provides an impetus for future research.

\section{CAN NEUROBIOLOGICAL VARIABLES ENHANCE PREDICTION OF PSYCHOSIS?}

Since all samples discussed in this review are preselected by clinical risk criteria, it remains unclear if objective measures would perform equally well as screening tools in non-selected, help-seeking samples. Furthermore, their predictive value beyond clinical criteria has still to be evaluated. However, different to any clinical approach, neurophysiological parameters provide an estimate of the remaining time until transition $(25,79)$, which is most important for targeted intervention. Another aspect relates to reliability. The clinical assessment of at-risk states needs highly trained specialists to overcome the clinical ambiguity of certain symptoms (80). Although technically not trivial, the objectivity of parameters of information processing might hence provide decisive advantage.

The specificity of neurobiological parameters represents another major topic. Neural information processing deficits have been observed in non-psychotic disorders, too, as well as in healthy individuals, although some parameters may be more specific to psychosis $(43,84-87)$. However, it appears debatable if any nonclinical approach should actually be intended to identify high-risk subjects irrespective of clinical criteria, e.g., in population samples. Currently, the best approach may be a two-step algorithm of risk detection and subsequent risk stratification (22). The integration of multiple different measures in a single step may increase specificity (82) but will likely result in an undesirably loss of sensitivity (22). A sequential algorithm of risk estimation would avoid this disadvantage by employing firstly measures with a high sensitivity (clinical risk criteria) and subsequently predictors with a presumably high specificity (e.g., parameters of information processing) (22). Such an approach may be best suited not only to validly identify high-risk subjects and enrich samples for research purposes, but also to enable stratification of risk and with that individualized risk estimation as a major step toward needs-adapted prevention. 


\section{CONCLUSION}

The heuristic implications of the basic disturbances concept predict that particularly aberrations of neural information processing represent the objective counterparts of cognitive and perceptive BS. The current literature provides evidence that information processing deficits can discriminate at-risk subjects converting to psychosis from those who will not develop a psychotic disorder. In fMRI investigations, group differences have been demonstrated particularly with regard to brain regions involved in language processing. Event-related potentials may enable a quantification of risk in terms of magnitude and time. Particularly the latter finding represents a significant advancement compared to clinical approaches. In synopsis of the literature,

\section{REFERENCES}

1. Harvey PD. Cognitive impairment in schizophrenia: profile, course, and neurobiological determinants. Handb Clin Neurol (2012) 106:433-45.

2. Nuechterlein KH, Dawson ME, Green MF. Information-processing abnormalities as neuropsychological vulnerability indicators for schizophrenia. Acta Psychiatr Scand Suppl (1994) 384:71-9. doi:10. 1111/j.1600-0447.1994.tb05894.x

3. Brunelin J, Mondino M, Gassab L, Haesebaert F, Gaha L, SuaudChagny MF, et al. Examining transcranial direct-current stimulation (tDCS) as a treatment for hallucinations in schizophrenia. Am J Psychiatry (2012) 169(7):719-24. doi: 10.1176/appi.ajp.2012.11071091

4. Huber G. Reine Defektsyndrome und Basisstadien endogener Psychosen. Fortschr Neurol Psychiatr (1966) 34:409-26.

5. Schultze-Lutter F, Ruhrmann S, Berning J, Maier W, Klosterkötter J. Basic symptoms and ultrahigh risk criteria: symptom development in the initial prodromal state. Schizophr Bull (2010) 36(1):182-91. doi: $10.1093 / \mathrm{schbul} / \mathrm{sbn} 072$

6. Klosterkötter J. The meaning of basic symptoms for the genesis of the schizophrenic nuclear syndrome. Jpn J Psychiatry Neurol (1992) 46(3):609-30.

7. Klosterkötter J, Schultze-Lutter F, Bechdolf A, Ruhrmann S. Prediction and prevention of schizophrenia: what has been achieved and where to go next? World Psychiatry (2011) 10(3):165-74.

8. Schultze-Lutter F, Ruhrmann S, Fusar-Poli P, Bechdolf A, Schimmelmann BG, Klosterkotter J. Basic symptoms and the prediction of first-episode psychosis. Curr Pharm Des (2012) 18(4):351-7. doi:10. 2174/138161212799316064

9. Stewart R. Subjective cognitive impairment. Curr Opin Psychiatry
(2012) 25(6):445-50. doi:10.1097/ YCO.0b013e3283586fd8

10. Knopman DS. Subjective cognitive impairment: fickle but fateful. Neurology (2012) 79(13):1308-9. doi: 10.1212/WNL.0b013e31826clbd1 Basisstörungen. In: Hippius H, Janzarik W, Müller C, editors. Berlin: Springer (1986).

12. Klosterkötter J. Basissymptome und Endphänomene der Schizophrenie Eine empirische Untersuchung der hen zwischen defizitären und produktiven Schizophreniesymptomen. In: Hippius H, Janzarik W, Müller C, editors. Berlin: Springer (1988).

13. Kapur S. Psychosis as a state of aberrant salience: a framework linking biology, phenomenology, and pharmacology in schizophrenia. Am J Psychiatry (2003) 160(1):13-23.

14. Klosterkötter J, Hellmich M, Steinmeyer EM, Schultze-Lutter F. Diagnosing schizophrenia in the initial prodromal phase. Arch Gen Psychiatry (2001) 58(2):158-64. doi:10. 1001/archpsyc.58.2.158

15. Schultze-Lutter F. Subjective symptoms of schizophrenia in research and the clinic: the basic symptom concept. Schizophr Bull (2009) 35(1):5-8. doi:10.1093/schbul/sbn139

16. Ruhrmann S, Schultze-Lutter F, Klosterkotter J. Early detection and intervention in the initial prodromal phase of schizophrenia. Pharmacopsychiatry (2003) 36(Suppl 3):S162-7. doi:10.1055/s-2003-45125

17. Schultze-Lutter F, Klosterkötter J, Picker H, Steinmeyer E, Ruhrmann S. Predicting first-episode psychosis by basic symptom criteria. Clin Neuropsychiatry (2007) 4:11-22.

18. Fusar-Poli P, Borgwardt S, Bechdolf A, Addington J, Riecher-Rossler
11. Süllwold L, Huber G. Schizophrene psychopathologischen Übergangsreidoi:10.1176/appi.ajp.160.1.13

some findings seem to support the assumed close relationship between self-experienced BS and neural information processing. Disturbances of language function have been identified as predictive symptoms in clinical BS studies and neural correlates have been demonstrated in both, fMRI and neurophysiological investigations. Even though the relationship between BS phenomenology and neural activity appears yet largely unknown in general, deficits in neurophysiological parameters seem to be more closely related to cognitive deficits than to psychotic symptoms.

Taken together, the BS concept provides not only a valid instrument in predicting psychosis onset but represents moreover a significant heuristic framework for future research.

A, Schultze-Lutter F, et al. The psychosis high-risk state: a comprehensive state-of-the-art review. JAMA Psychiatry (2013) 70(1):10720. doi:10.1001/jamapsychiatry. 2013.269

19. Yung AR, Phillips LJ, McGorry PD, McFarlane CA, Francey S, Harrigan S, et al. Prediction of psychosis. A step towards indicated prevention of schizophrenia. Br J Psychiatry Suppl (1998) 172(33):14-20.

20. Ruhrmann S, Schultze-Lutter F, Klosterkötter J. Sub-threshold states of psychosis - a challenge to diagnosis and treatment. Clin Neuropsychiatry (2010) 7(2):72-87.

21. Fusar-Poli P, Bonoldi I, Yung AR, Borgwardt S, Kempton MJ, Valmaggia L, et al. Predicting psychosis: meta-analysis of transition outcomes in individuals at high clinical risk. Arch Gen Psychiatry (2012) 69(3):220-9. doi:10.1001/ archgenpsychiatry.2011.1472

22. Ruhrmann S, Klosterkotter J, Bodatsch M, Nikolaides A, Julkowski D, Hilboll $\mathrm{D}$, et al. Chances and risks of predicting psychosis. Eur Arch Psychiatry Clin Neurosci (2012) 262(Suppl 2):S85-90. doi:10.1007/s00406-012-0361-4

23. Ruhrmann S, Schultze-Lutter F, Klosterkotter J. Probably at-risk, but certainly ill - advocating the introduction of a psychosis spectrum disorder in DSM-V. Schizophr Res (2010) 120(1-3):23-37. doi:10. 1016/j.schres.2010.03.015

24. Gross G, Huber G. Psychopathology of schizophrenia and brain imaging. Fortschr Neurol Psychiatr (2008) 76(Suppl 1):S49-56. doi:10.1055/s2008- 1038152

25. Bodatsch M, Ruhrmann S, Wagner M, Muller R, Schultze-Lutter F, Frommann I, et al. Prediction of psychosis by mismatch negativity. Biol Psychiatry (2011) 69(10):95966. doi:10.1016/j.biopsych.2010.09. 057
26. Meng H, Schimmelmann BG, Koch E, Bailey B, Parzer P, Gunter M, et al. Basic symptoms in the general population and in psychotic and non-psychotic psychiatric adolescents. Schizophr Res (2009) 111(13):32-8. doi:10.1016/j.schres.2009. 03.001

27. Schimmelmann BG, Michel C, Schaffner N, Schultze-Lutter F. What percentage of people in the general population satisfies the current clinical at-risk criteria of psychosis? Schizophr Res (2011) 125(1):99-100. doi:10.1016/ j.schres.2010.09.018

28. Koutsouleris N, Meisenzahl EM, Davatzikos C, Bottlender R, Frodl $\mathrm{T}$, Scheuerecker J, et al. Use of neuroanatomical pattern classification to identify subjects in at-risk mental states of psychosis and predict disease transition. Arch Gen Psychiatry (2009) 66(7):700-12. doi:10.1001/ archgenpsychiatry.2009.62

29. Bell RQ. Multiple-risk cohorts and segmenting risk as solutions to the problem of false positives in risk for the major psychoses. Psychiatry (1992) 55(4):370-81.

30. Pantelis C, Yucel M, Bora E, Fornito A, Testa R, Brewer WJ, et al. Neurobiological markers of illness onset in psychosis and schizophrenia: the search for a moving target. Neuropsychol Rev (2009) 19(3): 385-98. doi:10.1007/s11065-0099114- 1

31. Fusar-Poli P. Voxel-wise metaanalysis of fMRI studies in patients at clinical high risk for psychosis. $J$ Psychiatry Neurosci (2012) 37(2):106-12. doi:10.1503/jpn.110021

32. Pauly K, Seiferth NY, Kellermann T, Ruhrmann S, Daumann B, Backes $\mathrm{V}$, et al. The interaction of working memory and emotion in persons clinically at risk for psychosis: an fMRI pilot study. Schizophr Res (2010) 120(1-3):167-76. doi:10.1016/j.schres.2009.12.008 
33. Broome MR, Matthiasson P, FusarPoli P, Woolley JB, Johns LC, Tabraham $P$, et al. Neural correlates of movement generation in the "atrisk mental state.” Acta Psychiatr Scand (2010) 122(4):295-301. doi: 10.1111/j.1600-0447.2009.01524.x

34. Allen P, Stephan KE, Mechelli A, Day F, Ward N, Dalton J, et al. Cingulate activity and fronto-temporal connectivity in people with prodromal signs of psychosis. Neuroimage (2010) 49(1):947-55. doi:10.1016/j. neuroimage.2009.08.038

35. Wager TD, Smith EE. Neuroimaging studies of working memory: a meta-analysis. Cogn Affect Behav Neurosci (2003) 3(4):255-74. doi: 10.3758/CABN.3.4.255

36. Fusar-Poli P, Howes OD, Allen P, Broome M, Valli I, Asselin MC, et al. Abnormal prefrontal activation directly related to pre-synaptic striatal dopamine dysfunction in people at clinical high risk for psychosis. Mol Psychiatry (2011) 16(1):67-75. doi:10.1038/mp.2009.108

37. Howes OD, Montgomery AJ, Asselin MC, Murray RM, Valli I, Tabraham $\mathrm{P}$, et al. Elevated striatal dopamine function linked to prodromal signs of schizophrenia. Arch Gen Psychiatry (2009) 66(1):13-20. doi:10. 1001/archgenpsychiatry.2008.514

38. Fusar-Poli P, Broome MR, Matthiasson P, Woolley JB, Johns LC, Tabraham $\mathrm{P}$, et al. Spatial working memory in individuals at high risk for psychosis: longitudinal fMRI study. Schizophr Res (2010) 123(1):45-52. doi:10.1016/j.schres

39. Fusar-Poli P, Broome MR, Matthiasson P, Woolley JB, Mechelli A, Johns LC, et al. Prefrontal function at presentation directly related to clinical outcome in people at ultrahigh risk of psychosis. Schizophr Bull (2011) 37(1):189-98. doi: $10.1093 / \mathrm{schbul} / \mathrm{sbp} 074$

40. Jung WH, Jang JH, Shin NY, Kim $\mathrm{SN}$, Choi CH, An SK, et al. Regional brain atrophy and functional disconnection in Broca's area in individuals at ultra-high risk for psychosis and schizophrenia. PLoS ONE (2012) 7(12):e51975. doi:10. 1371/journal.pone.0051975

41. Allen P, Luigjes J, Howes OD, Egerton A, Hirao K, Valli I, et al. Transition to psychosis associated with prefrontal and subcortical dysfunction in ultra high-risk individuals. Schizophr Bull (2012) 38(6):1268-76. doi:10.1093/schbul/ sbr194

42. Sabb FW, van Erp TG, Hardt ME, Dapretto M, Caplan R, Cannon $\mathrm{TD}$, et al. Language network dysfunction as a predictor of outcome in youth at clinical high risk for psychosis. Schizophr Res (2010) 116(2-3):173-83. doi:10. 1016/j.schres.2009.09.042

43. Javitt DC. Sensory processing in schizophrenia: neither simple nor intact. Schizophr Bull (2009) 35(6):1059-64. doi:10.1093/schbul/sbp110

44. Lee SY, Namkoong K, Cho HH, Song DH, An SK. Reduced visual P300 amplitudes in individuals at ultrahigh risk for psychosis and firstepisode schizophrenia. Neurosci Lett (2010) 486(3):156-60. doi:10.1016/ j.neulet.2010.09.035

45. Wolwer W, Brinkmeyer J, Stroth S, Streit M, Bechdolf A, Ruhrmann $\mathrm{S}$, et al. Neurophysiological correlates of impaired facial affect recognition in individuals at risk for schizophrenia. Schizophr Bull (2012) 38(5):1021-9. doi:10.1093/ schbul/sbr013

46. Bramon E, Rabe-Hesketh S, Sham P, Murray RM, Frangou S. Metaanalysis of the P300 and P50 waveforms in schizophrenia. Schizophr Res (2004) 70(2-3):315-29. doi:10. 1016/j.schres.2004.01.004

47. Brockhaus-Dumke A, SchultzeLutter F, Mueller R, Tendolkar I, Bechdolf A, Pukrop R, et al. Sensory gating in schizophrenia: P50 and N100 gating in antipsychotic-free subjects at risk, first-episode, and chronic patients. Biol Psychiatry (2008) 64(5):376-84. doi:10.1016/j.biopsych.2008.02.006

48. Umbricht D, Krljes S. Mismatch negativity in schizophrenia: a meta-analysis. Schizophr Res (2005) 76(1):1-23. doi:10.1016/j.schres.2004.12.002

49. Cadenhead KS, Light GA, Shafer KM, Braff DL. P50 suppression in individuals at risk for schizophrenia: the convergence of clinical, familial, and vulnerability marker risk assessment. Biol Psychiatry (2005) 57(12):1504-9. doi:10.1016/ j.biopsych.2005.03.003

50. Hsieh MH, Shan JC, Huang WL, Cheng WC, Chiu MJ, Jaw FS, et al. Auditory event-related potential of subjects with suspected pre-psychotic state and first-episode psychosis. Schizophr Res (2012) 140(1-3):243-9. doi:10.1016/j.schres.2012.06.021

51. Myles-Worsley M, Ord L, Blailes F, Ngiralmau H, Freedman R. P50 sensory gating in adolescents from a pacific island isolate with elevated risk for schizophrenia. Biol Psychiatry (2004) 55(7):663-7. doi: 10.1016/j.biopsych.2003.12.006
52. van Tricht MJ, Nieman DH, Koelman JT, Mensink AJ, Bour LJ, van der Meer JN, et al. Sensory gating in subjects at ultra high risk for developing a psychosis before and after a first psychotic episode. World J Biol Psychiatry (2012). doi:10.3109/ 15622975.2012.680911

53. Ziermans T, Schothorst P, Magnee M, van Engeland H, Kemner C. Reduced prepulse inhibition in adolescents at risk for psychosis: a 2year follow-up study. J Psychiatry Neurosci (2011) 36(2):127-34. doi: 10.1503/jpn. 100063

54. Ziermans TB, Schothorst PF, Sprong M, Magnee MJ, van Engeland $\mathrm{H}$, Kemner C. Reduced prepulse inhibition as an early vulnerability marker of the psychosis prodrome in adolescence. Schizophr Res (2012) 134(1):10-5. doi:10.1016/j. schres.2011.10.009

55. Scholes KE, Martin-Iverson MT. Disturbed prepulse inhibition in patients with schizophrenia is consequential to dysfunction of selective attention. Psychophysiology (2010) 47(2):223-35. doi:10.1111/j. 1469-8986.2009.00927.x

56. Thaker GK. Neurophysiological endophenotypes across bipolar and schizophrenia psychosis. Schizophr Bull (2008) 34(4):760-73. doi:10. 1093/schbul/sbn049

57. Turetsky BI, Calkins ME, Light GA, Olincy A, Radant AD, Swerdlow NR. Neurophysiological endophenotypes of schizophrenia: the viability of selected candidate measures. Schizophr Bull (2007) 33(1):69-94. doi:10.1093/schbul/sbl060

58. Kenemans JL, Kahkonen S. How human electrophysiology informs psychopharmacology: from bottom-up driven processing to top-down control. Neuropsychopharmacology (2011) 36(1):2651. doi:10.1038/npp.2010.157

59. Atkinson RJ, Michie PT, Schall U. Duration mismatch negativity and P3a in first-episode psychosis and individuals at ultra-high risk of psychosis. Biol Psychiatry (2012) 71(2):98-104. doi:10.1016/j. biopsych.2011.08.023

60. Brockhaus-Dumke A, Tendolkar I, Pukrop R, Schultze-Lutter F, Klosterkötter J, Ruhrmann S. Impaired mismatch negativity generation in prodromal subjects and patients with schizophrenia. Schizophr Res (2005) 73(2-3):297-310. doi:10.1016/j.schres.2004.05.016

61. Higuchi Y, Sumiyoshi T, Seo T, Miyanishi T, Kawasaki Y, Suzuki M. Mismatch negativity and cognitive performance for the prediction of psychosis in subjects with at-risk mental state. PLOS ONE (2013) 8(1):e54080. doi:10.1371/ journal.pone. 0054080

62. Jahshan C, Cadenhead KS, Rissling AJ, Kirihara K, Braff DL, Light GA. Automatic sensory information processing abnormalities across the illness course of schizophrenia. Psychol Med (2012) 42(1):85-97. doi: 10.1017/S0033291711001061

63. Shaikh M, Valmaggia L, Broome MR, Dutt A, Lappin J, Day F, et al. Reduced mismatch negativity predates the onset of psychosis. Schizophr Res (2012) 134(1): 42-8. doi:10.1016/j.schres.2011.09. 022

64. Shin KS, Kim JS, Kang DH, Koh Y, Choi JS, O'Donnell BF, et al. Pre-attentive auditory processing in ultra-high-risk for schizophrenia with magnetoencephalography. Biol Psychiatry (2009) 65(12):1071-8. doi:10.1016/j.biopsych.2008.12.024

65. Mondragon-Maya A, Solis-Vivanco R, Leon-Ortiz P, RodriguezAgudelo Y, Yanez-Tellez G, BernalHernandez J, et al. Reduced P3a amplitudes in antipsychotic naive first-episode psychosis patients and individuals at clinical highrisk for psychosis. J Psychiatr Res (2013) 47(6):755-61. doi:10.1016/j. jpsychires.2012.12.017

66. Garrido MI, Kilner JM, Stephan KE, Friston KJ. The mismatch negativity: a review of underlying mechanisms. Clin Neurophysiol (2009) 120(3):453-63. doi:10.1016/ j.clinph.2008.11.029

67. Schall U, Johnston P, Todd J, Ward PB, Michie PT. Functional neuroanatomy of auditory mismatch processing: an event-related fMRI study of duration-deviant oddballs. Neuroimage (2003) 20(2):72936. doi:10.1016/S1053-8119(03) 00398-7

68. Kreitschmann-Andermahr I, Rosburg T, Demme U, Gaser E, Nowak $\mathrm{H}$, Sauer H. Effect of ketamine on the neuromagnetic mismatch field in healthy humans. Brain Res Cogn Brain Res (2001) 12(1):109-16. doi: 10.1016/S0926-6410(01)00043-X

69. Umbricht D, Koller R, Vollenweider FX, Schmid L. Mismatch negativity predicts psychotic experiences induced by NMDA receptor antagonist in healthy volunteers. Biol Psychiatry (2002) 51(5): 400-6. doi:10.1016/S00063223(01)01242-2

70. Fusar-Poli P, Crossley N, Woolley J, Carletti F, Perez-Iglesias R, Broome $\mathrm{M}$, et al. White matter alterations related to P300 
abnormalities in individuals at high risk for psychosis: an MRIEEG study. J Psychiatry Neurosci (2011) 36(4):239-48. doi:10.1503/ jpn.100083

71. Fusar-Poli P, Crossley N, Woolley J, Carletti F, Perez-Iglesias R, Broome $\mathrm{M}$, et al. Gray matter alterations related to P300 abnormalities in subjects at high risk for psychosis: longitudinal MRI-EEG study. Neuroimage (2011) 55(1):320-8. doi:10. 1016/j.neuroimage.2010.11.075

72. van der Stelt $\mathrm{O}$, Lieberman JA, Belger A. Auditory P300 in high-risk, recent-onset and chronic schizophrenia. Schizophr Res (2005) 77(2-3):309-20. doi:10.1016/j.schres.2005.04.024

73. van Tricht MJ, Nieman DH, Koelman JH, van der Meer JN, Bour LJ, de Haan L, et al. Reduced parietal P300 amplitude is associated with an increased risk for a first psychotic episode. Biol Psychiatry (2010) 68(7):642-8. doi:10.1016/j. biopsych.2010.04.022

74. Frommann I, Brinkmeyer J, Ruhrmann S, Hack E, BrockhausDumke A, Bechdolf A, et al. Auditory P300 in individuals clinically at risk for psychosis. Int $J$ Psychophysiol (2008) 70(3):192-205. doi:10.1016/j.ijpsycho.2008.07.003

75. Ozgurdal S, Gudlowski Y, Witthaus H, Kawohl W, Uhl I, Hauser $M$, et al. Reduction of auditory event-related P300 amplitude in subjects with at-risk mental state for schizophrenia. Schizophr
Res (2008) 105(1-3):272-8. doi:10. 1016/j.schres.2008.05.017

76. Bramon E, Shaikh M, Broome M, Lappin J, Berge D, Day F, et al. Abnormal P300 in people with high risk of developing psychosis. Neuroimage (2008) 41(2):553-60. doi: 10.1016/j.neuroimage.2007.12.038

77. Potter D, Summerfelt A, Gold J, Buchanan RW. Review of clinical correlates of P50 sensory gating abnormalities in patients with schizophrenia. Schizophr Bull (2006) 32(4):692-700. doi:10.1093/schbul/ sbj050

78. Murphy J, Blanchard MM, Rawdon C, Kavanagh F, Kelleher I, Clarke MC, et al. Language processing abnormalities in adolescents with psychotic-like experiences: an event related potential study. Schizophr Res (2012) 137(1-3):91-6. doi: 10.1016/j.schres.2012.01.017

79. Perez V. MMN as a predictor of psychosis and a correlate of function in schizophrenia. 6th Conference on Mismatch Negativity (MMN) and Its Clinical and Scientific Application; New York (2012).

80. Yung AR, Nelson B, Stanford C, Simmons MB, Cosgrave EM, Killackey E, et al. Validation of "prodromal" criteria to detect individuals at ultra high risk of psychosis: 2 year followup. Schizophr Res (2008) 105(13):10-7. doi:10.1016/j.schres.2008. 07.012

81. Addington J, Heinssen R. Prediction and prevention of psychosis in youth at clinical high risk. Annu
Rev Clin Psychol (2012) 8:269-89. doi:10.1146/annurev-clinpsy032511-143146

82. Zimmermann R, Gschwandtner U, Wilhelm FH, Pflueger MO, RiecherRossler A, Fuhr P. EEG spectral power and negative symptoms in at-risk individuals predict transition to psychosis. Schizophr Res (2010) 123(2-3):208-16. doi:10. 1016/j.schres.2010.08.031

83. Papeo L, Pascual-Leone A, Caramazza A. Disrupting the brain to validate hypotheses on the neurobiology of language. Front Hum Neurosci (2013) 7:148. doi:10.3389/ fnhum. 2013.00148

84. Javitt DC. When doors of perception close: bottom-up models of disrupted cognition in schizophrenia. Annu Rev Clin Psychol (2009) 5:249-75. doi:10.1146/ annurev.clinpsy.032408.153502

85. Kaur M, Lagopoulos J, Ward PB, Watson TL, Naismith SL, Hickie IB, et al. Mismatch negativity/P3a complex in young people with psychiatric disorders: a cluster analysis. PLoS ONE (2012) 7(12): e51871. doi:10.1371/journal.pone. 0051871

86. Light GA, Swerdlow NR, Rissling AJ, Radant A, Sugar CA, Sprock J, et al. Characterization of neurophysiologic and neurocognitive biomarkers for use in genomic and clinical outcome studies of schizophrenia. PLoS ONE (2012) 7(7): e39434. doi:10.1371/journal.pone. 0039434
87. Michie PT, Innes-Brown H, Todd J, Jablensky AV. Duration mismatch negativity in biological relatives of patients with schizophrenia spectrum disorders. Biol Psychiatry (2002) 52(7):749-58. doi:10.1016/ S0006-3223(02)01379-3

Conflict of Interest Statement: The authors declare that the research was conducted in the absence of any commercial or financial relationships that could be construed as a potential conflict of interest.

Received: 14 May 2013; accepted: 09 August 2013; published online: 23 August 2013.

Citation: Bodatsch M, Klosterkötter J, Müller R and Ruhrmann S (2013) Basic disturbances of information processing in psychosis prediction. Front. Psychiatry 4:93. doi: 10.3389/fpsyt.2013.00093

This article was submitted to Schizophrenia, a section of the journal Frontiers in Psychiatry.

Copyright $\odot 2013$ Bodatsch, Klosterkötter, Müller and Ruhrmann. This is an open-access article distributed under the terms of the Creative Commons Attribution License (CC BY). The use, distribution or reproduction in other forums is permitted, provided the original author(s) or licensor are credited and that the original publication in this journal is cited, in accordance with accepted academic practice. No use, distribution or reproduction is permitted which does not comply with these terms. 